\title{
Is there a role for menopausal hormone therapy in the management of postmenopausal osteoporosis?
}

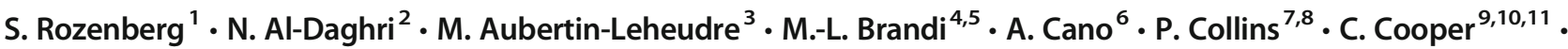

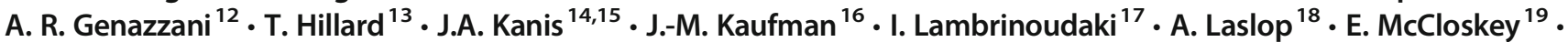

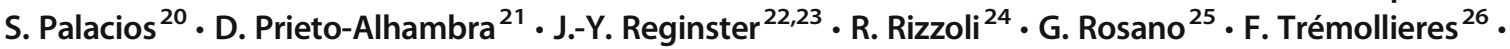 \\ N.C. Harvey ${ }^{9,10}$
}

Received: 10 March 2020 / Accepted: 4 May 2020 / Published online: 8 July 2020

(C) The Author(s) 2020

\begin{abstract}
We provide an evidence base and guidance for the use of menopausal hormone therapy (MHT) for the maintenance of skeletal health and prevention of future fractures in recently menopausal women. Despite controversy over associated side effects, which has limited its use in recent decades, the potential role for MHT soon after menopause in the management of postmenopausal osteoporosis is increasingly recognized. We present a narrative review of the benefits versus risks of using MHT in the management of postmenopausal osteoporosis. Current literature suggests robust anti-fracture efficacy of MHT in patients unselected for low BMD, regardless of concomitant use with progestogens, but with limited evidence of persisting skeletal benefits following cessation of therapy. Side effects include cardiovascular events, thromboembolic disease, stroke and breast cancer, but the benefit-risk profile differs according to the use of opposed versus unopposed oestrogens, type of oestrogen/ progestogen, dose and route of delivery and, for cardiovascular events, timing of MHT use. Overall, the benefit-risk profile supports MHT treatment in women who have recently (<10 years) become menopausal, who have menopausal symptoms and who are less than 60 years old, with a low baseline risk for adverse events. MHT should be considered as an option for the maintenance of skeletal health in women, specifically as an additional benefit in the context of treatment of menopausal symptoms, when commenced at the menopause, or shortly thereafter, in the context of a personalized benefit-risk evaluation.
\end{abstract}

Key messages - Overall the benefit-risk balance for MHT use is more favourable at the age of menopause or in the years thereafter, for example before the age of 60 years and/or within 10 years after menopause, and for unopposed oestrogen (used in hysterectomized women) compared with combined oestrogen plus progestogen in women with an intact uterus.

- There is some evidence that the risk of cardiovascular outcomes depends upon age/time from menopause, such that, particularly for oestrogen only therapy, the risk of such outcomes may be lower when hormone therapy is commenced early postmenopause compared with in older age. This temporal relationship is less well-defined for combined oestrogenprogestogen therapy.

- Transdermal preparations are associated with lower risk of thromboembolic outcomes and are as effective as oral preparations for maintenance of BMD, but their effect on fracture risk reduction is unproven.

- Overall, MHT may be considered as an option for the maintenance of bone health in menopausal women, as an additional benefit in the context of treatment of menopausal symptoms, amongst women who are at low risk of breast cancer and of cardiovascular, cerebrovascular and venous thromboembolic events and who do not warrant a specific skeletal therapy such as a bisphosphonate.

N.C. Harvey

nch@mrc.soton.ac.uk

Extended author information available on the last page of the article 
Keywords Cardiovascular $\cdot$ Epidemiology $\cdot$ Hormone therapy $\cdot$ Menopause $\cdot$ Osteoporosis $\cdot$ Safety

\section{Introduction}

Over the last three decades, osteoporosis has progressed from being viewed as an inevitable consequence of ageing to being understood as a major non-communicable chronic disease, with an associated diagnostic definition and effective methods of detection, risk stratification and treatment $[1,2]$. We are fortunate now to have a wide range of therapeutic strategies for managing osteoporosis, targeted at improving or maintaining bone mineral density $[3,4]$. Across the various pharmaceutical interventions available, it is possible to view particular therapies as most appropriately targeted to particular stages of the risk spectrum. For example, oral bisphosphonate therapy may be appropriate where there is established osteoporosis and high risk of fracture [3]. In a recent position paper from the European Society for the Clinical and Economic Aspects of Osteoporosis, Osteoarthritis and Musculoskeletal Diseases (ESCEO) and the International Osteoporosis Foundation (IOF), we described how this appreciation of stratification according to efficacy, costs and side effects, in relation to low, high and very high fracture risk, might be implemented in clinical practice [5]. A key consideration in this work was the approach to women who were currently at low risk but who might well become at high risk in older age and whether interventions based on the high lifetime risk of fracture, rather than the immediate low risk of fracture, might be advised. One class of medication that is highly relevant here is menopausal hormone therapy (MHT), given the clear evidence for its antifracture efficacy, regardless of baseline bone mineral density, and also for the relevant ameliorative effects on menopausal symptoms [6].

MHT was widely used in the 1980s and 1990s for the prevention of symptoms associated with the menopause, such as hot flushes, night sweats and sleep disturbance, with the widely prevailing view that prevention of cardiovascular disease and osteoporosis were additional benefits [7, 8]. The rationale for such an approach was an evidence-base consisting principally of observational studies, in which the use of hormone replacement therapy (as it was known at that time) was associated with generally improved health outcomes, particularly in relation to cardiovascular disease. This whole thesis was challenged by results from the large US Women's Health Initiative (WHI) Hormone Therapy trials, the first of which compared a fixed composition of conjugated equine oestrogens (CEE) and medroxyprogesterone acetate (MPA) to placebo and was published in $2002[7,9]$. This trial reported that, whilst this hormone therapy regimen did indeed lead to a decreased risk of fractures, it was associated with increased risks of cardiovascular and cerebrovascular events, as well as with increased risks of breast cancer and other adverse health outcomes [10]. Subsequently, the limitations of inadequately analysed, confounded observational studies and the potential for converse findings from well conducted randomized controlled trials have found a key exemplum in the MHT story [11]. Interestingly, when the original observational studies were re-analysed using state-of-the-art pharmacoepidemiology techniques, which much more effectively control problems such as confounding by indication, then findings more in line with the results from randomized trials were observed [11]. However, these remain analyses of observational studies and therefore should be viewed as less robust evidence than those derived from randomized trials. Subsequent re-analyses of the WHI trials, together with evidence from other trials, have suggested that the benefit-risk profiles of MHT differ according to the timing of use in relation to the menopause and chronological age and by MHT regimen (addition or not of progestogen, type of oestrogen and progestogen, dose of oestrogen and route of administration) [7-9].

There is clearly a complex evidential landscape in which to assess the role of MHT in the prevention/treatment of osteoporosis. In this position paper, based on a narrative literature review, we will use randomized controlled trial evidence and meta-analyses thereof, in order to use the best quality data. Additionally, we focus on the scenario of normal menopause, rather than premature ovarian insufficiency, for which MHT, to replace the hormone deficit, is generally appropriate [12]. We firstly describe the natural history of the menopause in terms of hormonal changes and consequent health outcomes; subsequently, we set out the evidence that MHT is effective in reducing the risk of incident fracture, the independence of this effect from baseline BMD and age. Thereafter, we aim to examine the overall benefit-risk profile of MHT, particularly with regard to cardiovascular outcomes, and to investigate the potential effects of timing in relation to menopausal transition, dose and route of administration as approaches to mitigate adverse effects. We conclude by assessing the potential health economic aspects of the use of MHT for fracture prevention and outline a potential clinical approach.

\section{Natural history of hormonal changes at the menopause and associated health outcomes}

\section{Menopausal physiology}

The menopause is defined as the permanent cessation of menstruation that results from loss of ovarian follicular activity. Clinically, in women in their 40 s or 50 s, it is recognized to 
have occurred after twelve consecutive months of amenorrhoea for which no other obvious pathological or physiological cause can be found. In most women, the menopause is preceded by a phase of about 4 years during which the endocrine, biological and clinical features of changing ovarian function occur $[13,14]$. In a normal menstrual cycle, the ovaries produce oestrogens (i.e. oestradiol), androgens (i.e. testosterone) and progesterone in a cyclical pattern under the control of follicle stimulating hormone (FSH) and luteinizing hormone ( $\mathrm{LH})$, which are secreted by the pituitary gland. In the early menopausal phase (perimenopause), oestradiol levels may remain relatively similar to those in young women (or may even be higher), but cycles frequently become shorter or irregular. The depletion of the ovarian reserve with age, a consequence of the finite number of oocytes and the consequent reduced levels of oestrogen, leads to an increase in circulating follicle-stimulating hormone (FSH) and luteinizing hormone (LH) levels. In contrast to the relatively rapid decline in oestradiol during menopause, concentrations of total and free testosterone, as well as of dehydroepiandrosterone sulphate (DHEAS) and androstenedione, appear to fall rather more steadily with advancing age. Concentrations of progesterone are low postmenopause, and whilst circulating levels of oestrogen are markedly lower post- than premenopause, there may still be some oestrogenic activity at the intracellular level as a result of local aromatization of androgen precursors [15]. These hormonal changes lead to the wide range of symptoms associated with the menopause, such as hot flushes, sleep disturbance, mood changes and urogenital changes, which are described in detail elsewhere [16].

\section{Menopause and the skeleton}

In 1947, Fuller Albright published his observations on the causal relationship between oestrogen deficiency following the menopause and impaired bone health [17]. His work established the principles that treatment with exogenous oestrogen can help to maintain bone mass and thus to reduce fracture risk. Oestrogen appears to have direct activity on osteoclasts, osteoblasts and osteocytes, with the principal effects as an antiresorptive agent through reduction of osteoclast numbers and function, mediated through various pathways including the receptor activator of nuclear factor kappa B ligand (RANKL) system [18]. Impaired osteoblast activity in oestrogen deficiency is reflected in reduced matrix production as measured by mean wall thickness on bone histology, an effect that is reversed by oestrogen replacement [19]. The increase in fracture risk associated with the menopausal transition is well established, together with a period of accelerated bone loss, particularly trabecular (with a loss of bone structure, for example increased trabecular perforations, as well as loss of bone mass [20]), which then settles to a more long-term age-related decline. Interestingly, the presence of menopausal symptoms has been shown to be associated with spinal osteoporosis, supporting a dual benefit of MHT on both outcomes [21]. The incidence of fracture varies by age and site, such that wrist fractures become notable around the age of menopause and in the years soon after, whereas the incidences of vertebral and then hip fractures rise sharply at older ages [22, 23]. A wrist fracture may well be the warning sign for impaired bone health in the recently menopausal woman, and thus indicate the urgent necessity for risk assessment and preventive action to prevent further fracture events [22].

\section{Types of MHT (oestrogens, progestogens, dose, route of administration)}

MHT in its simplest form consists of an oestrogen, given either alone (where a woman has undergone hysterectomy) or together with a progestogen to reduce the risk of endometrial cancer where the uterus is still present. For example, the combination used in the WHI was oral conjugated equine oestrogen (CEE) $0.625 \mathrm{mg}$ /day and medroxyprogesterone acetate (MPA) $2.5 \mathrm{mg} /$ day. However, there is now a wide range of options, including other more physiological oestrogen compounds, such as oral micronized $17 \beta$-oestradiol (typically at a dose of $1-$ $2 \mathrm{mg}$ /day), and other progestogens, such as norethisterone acetate, micronized progesterone or dydrogesterone. Additionally, there are preparations that can be administered via the transdermal or percutaneous route (for example transdermal $17 \beta$ oestradiol typically at $25-50 \mu \mathrm{g} /$ day), and across routes of administration, various doses are now available [24]. Transdermal absorption of oestrogen bypasses first pass metabolism in the liver and appears not to alter the risk of venous thromboembolic disease and stroke, certainly much less than do oral oestrogens $[25,26]$. Whilst the progestogen component of MHT is given to reduce the risk of endometrial cancer, it should be noted that the benefit-risk profile of unopposed and opposed oestrogen MHT is rather different [8]. Finally, for completeness, tibolone (a synthetic steroid with mixed oestrogenic, progestogenic and androgenic activity) [27] and TSEC (Tissue Selective Oestrogen complex containing CEE and bazedoxifene) are also available for menopause treatment, although, as with other medications, their use and availability vary from country to country [24]. Given these complexities, it is critical to take a particular MHT preparation on its own merits and individualize treatment as far as the evidence will permit. For more specific information regarding doses and preparations, the reader is directed elsewhere [16].

\section{Efficacy of MHT for fracture prevention}

The initial seminal intervention studies, undertaken by Christiansen and colleagues in relatively small numbers of 
women, demonstrated protective effects of oestrogen with or without progestogen on bone mass, assessed using single or dual photon absorptiometry [28-30]. A US trial additionally demonstrated effects on bone histomorphometric parameters [31]. The first randomized trial evidence using dual-energy Xray absorptiometry (DXA) to show that MHT maintains bone mineral density (BMD) after the menopause came from the Postmenopausal Oestrogen/Progestin Intervention (PEPI) trial, published in 1996 [32]. It was the results of the WHI that demonstrated the anti-fracture efficacy of MHT, a finding that applied to all osteoporosis-related fractures, including those at the hip, and importantly in a population that was unselected for low BMD. Thus, amongst the 16,608 women aged 5079 years with an intact uterus at baseline who were randomized to either CEE+MPA or matching placebo, over a mean of 5.2 years follow-up, there was a $34 \%$ reduction in the incidence of hip fracture [Hazard Ratio (HR): 0.66; 95\% CI: 0.45 to 0.98 ]. A very similar effect was observed on the incidence of clinical vertebral fractures and a reduction in other osteoporotic fractures was documented (HR: $0.77 ; 95 \%$ CI: 0.69 to 0.86) [10]. A second analysis with 5.6 years of follow-up on active treatment again demonstrated a statistically significant reduction in fracture risk for the CEE+MPA group compared with placebo (HR: $0.76 ; 95 \%$ CI: 0.69 to 0.83 ). This effect was not modified by a range of factors such as age, body mass index, smoking status, prior falls, personal/family history of fracture, total calcium intake, past use of hormone therapy and importantly was independent of baseline BMD. A $3.7 \%$ increase in total hip BMD was noted at 3 years of treatment compared with a $0.14 \%$ increase in the placebo group [33].

The persistence, or otherwise, of a bone protective effect of MHT is an important consideration for its place in osteoporosis management. In a small early study, women $(n=347)$ who had previously been enrolled in one of four placebo-controlled MHT trials were re-examined at 5,11 or 15 years after stopping MHT [34]. Here, although rates of bone loss after stopping MHT returned to normal postmenopausal values, the BMD of previously MHT-treated women continued, for many years after cessation of treatment, to be higher than that of women who had received placebo. Furthermore, the risk of all osteoporotic fractures was lower in the previously MHTtreated than previously placebo-treated group [34]. However, several other studies both at the mechanistic [35] and population level have suggested that protective skeletal effects of MHT do not convincingly persist after cessation of therapy. Thus, amongst 140,584 postmenopausal women who participated in the US National Osteoporosis Risk Assessment study, those women who had discontinued MHT in the past 5 years had a 1-year hip fracture risk similar to women who had never used MHT [36]. Similar findings came from a study using the US Southern California Kaiser Permanente health management organization database. A total of 80,955 postmenopausal women using MHT were followed for around
6.5 years [37]. Women who discontinued MHT were at 55\% greater risk of hip fracture compared with those who continued, with the risk increasing as early as 2 years after cessation of MHT. Clearly, these observational studies may be more prone to bias and confounding than randomized trials. However, in the WHI, 3 years after cessation of the MHT intervention [38], in further analyses at a median follow-up of 4.8 years postintervention [39] and then in extended followup (8.2 years CEE+MPA and 6.6 years CEE only) postintervention, there was no evidence of any residual benefit from prior MHT for hip fractures, although rates were lower in the intervention than placebo group across the combined intervention and post-intervention follow-up [39, 40]. A further fracture-focused WHI analysis, examining women during 5 years of postintervention follow-up, who had been previously randomized to MHT or placebo again found that there was no evidence of either transiently or persistently decreased fracture risk amongst former MHT users compared with former placebo users. However, there was some evidence of a persisting benefit on total fractures amongst former MHT users who had taken part in the CEE-alone trial (who had undergone hysterectomy prior to baseline) but not in the CEE+MPA trial [41].

The WHI programme, with its several trials randomizing women to MHT versus placebo and calcium+vitamin D supplementation versus placebo, yielded a total of 16,089 women in whom an interaction between MHT and calcium+vitamin D supplementation on fracture risk reduction could be investigated. Indeed, there was evidence of an interaction between hormone therapy and calcium+vitamin D supplementation on hip fracture $(p$-interaction $=0.01)$. The effect of calcium+vitamin D supplementation was greater amongst women assigned to MHT (HR: 0.59 ; 95\%CI: 0.38 to 0.93 ) than placebo (HR: 1.20 ; $95 \%$ CI: 0.85 to 1.69$)$. Furthermore, the effect of hormone therapy (vs hormone therapy placebo) on hip fracture was greater amongst women assigned to calcium+vitamin D supplementation (HR: 0.43 ; 95\% CI: 0.28 to 0.66 ) than those women assigned to the placebo of the calcium+vitamin $\mathrm{D}$ randomization (HR: 0.87 ; 95\% CI: 0.60 to 1.26 ). Interestingly, there was no apparent interaction of MHT with calcium+vitamin D supplementation on hip or spine BMD changes, leading to questions regarding the underlying mechanism. However, the findings do suggest a synergistic benefit between these two interventions on fracture reduction [42]. Finally, in a meta-analysis of 28 studies including 33,426 participants and 2516 fracture cases, bone protective effects were consistent with those observed in WHI, with the HR for all fractures (MHT vs placebo) $0.74 ; 95 \%$ CI: 0.69 to 0.80 . Effect sizes were similar for hip (HR: $0.72 ; 95 \%$ CI: 0.53 to 0.98 ) and vertebral (HR: $0.63 ; 95 \%$ CI: 0.44 to 0.91 ) fractures [43]. Studies examining lower doses and transdermal applications (for example doses of $0.3 \mathrm{mg}$ /day oral conjugated oestrogens, $0.25 \mathrm{mg}$ /day oral micronized $17 \beta$-oestradiol or 
$14 \mu \mathrm{g} /$ day transdermal oestradiol) have suggested positive effects on bone mineral density, but definitive fracture outcome data are scarce $[24,44]$.

\section{Safety profile of MHT}

\section{Women's Health Initiative: overview and key findings}

The Women's Health Initiative (WHI) hormone studies comprised two MHT randomized controlled trials, including 27,347 postmenopausal women age 50-79 years [7,8]. Although these women were a generally healthy population, it should be noted that $35 \%$ had treated hypertension, $50 \%$ were past/current smokers and $34 \%$ had a body mass index greater than $30 \mathrm{~kg} / \mathrm{m}^{2}$ [10]. In order to accommodate the established risk of unopposed oestrogen for endometrial cancer, women with an intact uterus $(n=16,608)$ were randomized to conjugated equine oestrogens (CEE) $0.625 \mathrm{mg}$ /day, together with an oral progestin [medroxyprogesterone acetate (MPA) $2.5 \mathrm{mg} /$ day) or placebo. Those women who had had a hysterectomy $(n=10,739)$ were included in the oestrogen alone trial, with randomization to CEE $0.625 \mathrm{mg}$ /day versus matched placebo. The aim of these trials was to assess the impact of MHT on chronic non-communicable diseases of ageing such as cardiovascular outcomes, and therefore the sample sizes were chosen to have sufficient power to detect an effect on a composite outcome of coronary heart disease [non-fatal myocardial infarction (MI) or coronary death] and to assess the balance of benefits and risks over an 8.5 year treatment period. In fact, the two trials were stopped earlier than planned with the oestrogen-progestin trial halted after a median of 5.6 years of treatment (as a result of an observed increase in risk of breast cancer); the oestrogen alone trial was stopped after median of 7.2 years because of an increased risk of stroke in the CEE arm. The investigators continued to follow the participants for several years after cessation of the intervention and thus in the combined trial, median follow-up post intervention was 8.2 years; in the CEE alone trial, median postintervention follow-up was 6.6 years. The findings from WHI completely altered the clinical approach to MHT, with the prevalence of hormone therapy use in the US and Europe, declining sharply after publication of the first results in 2002. Data from the US National Health and Nutrition Examination Survey demonstrated a 22.4\% prevalence of MHT use 1999 to 2000 , declining to $11.9 \%$ in 2003-2004 with a more gradual further decline to $4.7 \%$ in 2009-2010 [45].

Thus, whilst the observational studies that preceded WHI had suggested a protective effect of MHT for cardiovascular outcomes; in the WHI trials, there was a modest increase in all cardiovascular events in women treated with hormone therapy. This was observed both with CEE+MPA (Hazard Ratio (HR): 1.13 ; 95\% CI: 1.02 to 1.25 ) and with CEE alone (HR:
$1.11 ; 95 \%$ CI: 1.01 to 1.22 ) during the intervention phases of the trials. The signal was also observed in the extended follow-up covering 13 years, with the HR (CEE+MPA): 1.08; $95 \%$ CI: 1.00 to 1.15 and HR (CEE alone): 1.06 ; $95 \%$ CI 0.98 to 1.15 [40]. Interestingly, during the first year of follow-up, there was an $80 \%$ increased risk of coronary heart disease events (non-fatal myocardial infarction or coronary death) with CEE+MPA compared with placebo, but which tapered off with time on treatment, a secular effect that was statistically significant $(p=0.03)$ [8]. It should be noted that the original analyses also included adjusted $95 \%$ CI to account for the repeated assessments of coronary heart disease (and breast cancer) outcomes and that these confidence intervals generally spanned unity. However, the investigators emphasized the unadjusted confidence intervals as the primary outcomes, which appears appropriate given the potential evidence for adverse effects [10]. A similar pattern of findings was observed in the final analysis of cardiovascular outcomes in the CEE+MPA trial, published a year later, with the absolute event rates for coronary heart disease events demonstrating the small excess in terms of absolute risk with 39 cases per 10,000 person-years in the hormone therapy and 33 per 10,000 person-years in the placebo group [46]. Venous thromboembolism was increased with both types of MHT, although more so with CEE+MPA. Thus, the HR for pulmonary embolism in the CEE+MPA trial was 1.98; 95\%CI: 1.36 to 2.87 , and in the same trial, the HR for deep vein thrombosis was 1.87 ; $95 \% \mathrm{CI}$ : 1.37 to 2.54 . The corresponding HRs in the CEE alone trial were 1.35 ; 95\%CI: 0.89 to 2.05 and 1.48 ; 95\% CI: 1.06 to 2.07 for pulmonary embolism and deep-vein thrombosis, respectively [40]. The HR for stroke with CEE+ MPA vs placebo was $1.37 ; 95 \%$ CI: 1.07 to 1.76 and with CEE alone vs placebo, $1.35 ; 95 \% \mathrm{CI}$ : 1.07 to 1.70 . The other major concern arising from WHI was the increased risk of breast cancer for women randomized to CEE+MPA compared with placebo (HR: $1.24 ; 95 \% \mathrm{CI}: 1.01$ to 1.53 ), which remained elevated during cumulative follow-up (HR: 1.28; 95\%CI: 1.11 to 1.48 ). Interestingly (and consistent with other data) [24], randomization to CEE alone was associated with a reduced risk (HR: 0.79: 95\%CI: 0.61 to 1.02 ), which persisted with time. Over the entire follow-up (after a mean of 10.7 years), lower breast cancer incidence in the CEE group persisted and was $0.27 \%$ compared with $0.35 \%$ in the placebo group (HR, 0.77; 95\%CI: 0.62 to 0.95) [39]. Conversely, CEE+MPA was associated with a reduction in colorectal cancer (HR: 0.62; 95\%I: 0.43 to 0.89 ) and evidence of a more modest reduction in endometrial cancer (HR: 0.83 ; 95\%CI: 0.49 to 1.40 ). With both MHT regimens, there were reductions in the risk of hip fracture, all fractures and type II diabetes, but an increase in gall bladder disease, urinary incontinence and the risk of dementia (only assessed in an older subset). In neither trial was the MHT intervention associated with mortality [40]. 
Finally, the pattern of cardiovascular events following discontinuation of MHT deserves consideration. Thus, amongst 332,202 Finnish women discontinuing MHT between 1994 and 2009, with data derived from national registries, previous MHT users had greater risk of cardiac (standardized mortality ratio (SMR), 95\%CI: $1.26 ; 1.16$ to 1.37 ) and stroke death (1.63; 1.47 to 1.79$)$ than expected over the first year post MHT cessation, but a lower risk thereafter (SMR: 0.75; 95\%CI: 0.72 to 0.78 and $0.89 ; 0.85$ to 0.94 respectively). Interestingly, the first year excess mortality seemed greater for women who had been $<60$ years old at MHT initiation or been users for $<5$ years, supporting the notion of differences in cardiovascular effects of MHT by age. The risk of both outcomes was consistently greater in those women who stopped MHT compared with those continuing [47]. A further analysis from the same group using national Finnish registry data and excluding women who experienced a cardiac or cerebrovascular event within the year before treatment cessation demonstrated similar excess mortality in the first year after stopping MHT compared with an age-matched female background population [48]. Although these observational findings do not prove a causal relationship and indeed may be influenced by, for example, cardiovascular/cerebrovascular related reasons for stopping (although the authors attempted to control for this in the later paper), these results do further support the vascular relevance of MHT.

\section{MHT and cardiovascular outcomes: does timing make a difference?}

A key consideration in the interpretation of the results of the WHI trial is that the average age of the participants was 63 years, which is markedly older than the average age of menopause in North America or Europe (51 years) [8]. Indeed, the majority of the WHI participants did not have symptoms of the menopausal transition [7]. This contrasts with the majority of the preceding observational studies, which generally enrolled younger women closer to the onset of menopause and usually with menopausal symptoms. The WHI investigators undertook analyses stratified by age, that is, effectively by years since menopause $[8,40]$. The findings, of a more favourable benefit-risk profile for those within 10 years of the menopause, compared with those women more than 10 years after menopause, have led to the concept of the "timing hypothesis" in relation to cardiovascular outcomes [8]. In this context, cardiovascular refers to arterial disease rather than to venous thromboembolism. Thus, in the WHI, when stratified by age, there was actually a reduction in myocardial infarction [HR: 0.55 ; 95\%CI: 0.31 to 1.00 ) and allcause mortality (HR: 0.70 ; 95\%CI: 0.46 to 1.09 ) in the 50 59 year age band for CEE alone compared with placebo. In contrast, those in the oldest age band (70-79 years) tended towards increased risks of these outcomes (HR: 1.24;
95\%CI: 0.88 to 1.75 and HR: 1.21 ; $95 \%$ CI: 0.95 to 1.56 for myocardial infarction and total mortality respectively). Although there were differences by age band for the CEE+ MPA trial, these were not so obviously linear, with the lowest hazard ratios usually in the 60-69 year age band compared with 50-59 years and 70-79 years. Interestingly, there appeared to be no effect by age band on relationships with stroke, breast cancer, fractures, diabetes or thromboembolic disease across either of the two hormone therapy regimens [40]. Indeed, breast cancer remains the other particularly concerning side effect of opposed MHT, and although beyond the scope of this review, the relevant evidence is discussed in detail elsewhere $[16,24]$. Figure 1 summarizes the absolute differences per 5000 person-years ( 1000 persons treated over 5 years) in number of events in the WHI hormone trials for women aged 50-59 years at enrolment.

\section{The timing hypothesis in trials subsequent to WHI}

Other intervention studies have investigated whether use of MHT early after the menopause might have protective effects on coronary artery disease, using measures of atherosclerosis such as carotid intima-media thickness and coronary artery calcification (summarized in Table 1). The majority of these were conducted post-WHI, but the Heart and Estrogen/ progestin Replacement Study (HERS) Research Trial yielded earlier relevant insights, albeit in the context of secondary prevention. A total of 2763 women with established coronary heart disease, who were younger than 80 years old (mean age 66.7 years) and postmenopausal with an intact uterus, were recruited across outpatient and community settings in 20 US clinical centres [49]. Women were randomized to either $0.625 \mathrm{mg}$ CEE plus $2.5 \mathrm{mg}$ of MPA $(n=1380)$ or matched placebo $(n=1383)$. Overall, there were no significant differences between groups in the primary outcome of non-fatal myocardial infarction or coronary heart disease (CHD) death [Relative hazard (RH), 0.99 ; 95\% CI: 0.80 to 1.22 ] or in any of the secondary cardiovascular outcomes. There was a net $11 \%$ lower low-density lipoprotein cholesterol level and $10 \%$ higher high-density lipoprotein cholesterol level in the hormone group compared with the placebo group. Within the overall null effect, there was a statistically significant time trend, with more CHD events in the hormone group than in the placebo group in year one and fewer in years four and five. More women in the hormone group than in the placebo group experienced venous thromboembolic events (34 vs 12; RH: 2.89; $95 \%$ CI: 1.50 to 5.58 ) and gallbladder disease ( 84 vs 62 ; RH: 1.38 ; $95 \%$ CI: 1.00 to 1.92 ). So here across the mean 4.1 years follow-up, there was a null effect on cardiovascular endpoints overall but with evidence of greater risk early during follow-up and reduced risk later, as well as an increased risk for venous thromboembolic events [49]. Given the potential for loss to follow-up and reduced adherence with time (for 
Fig. 1 Updated summary of the effects of orally administered $\mathrm{CEE}$ alone or combined with MPA in women ages 50-59 years during intervention phase of WHI (reused with permission from [9])

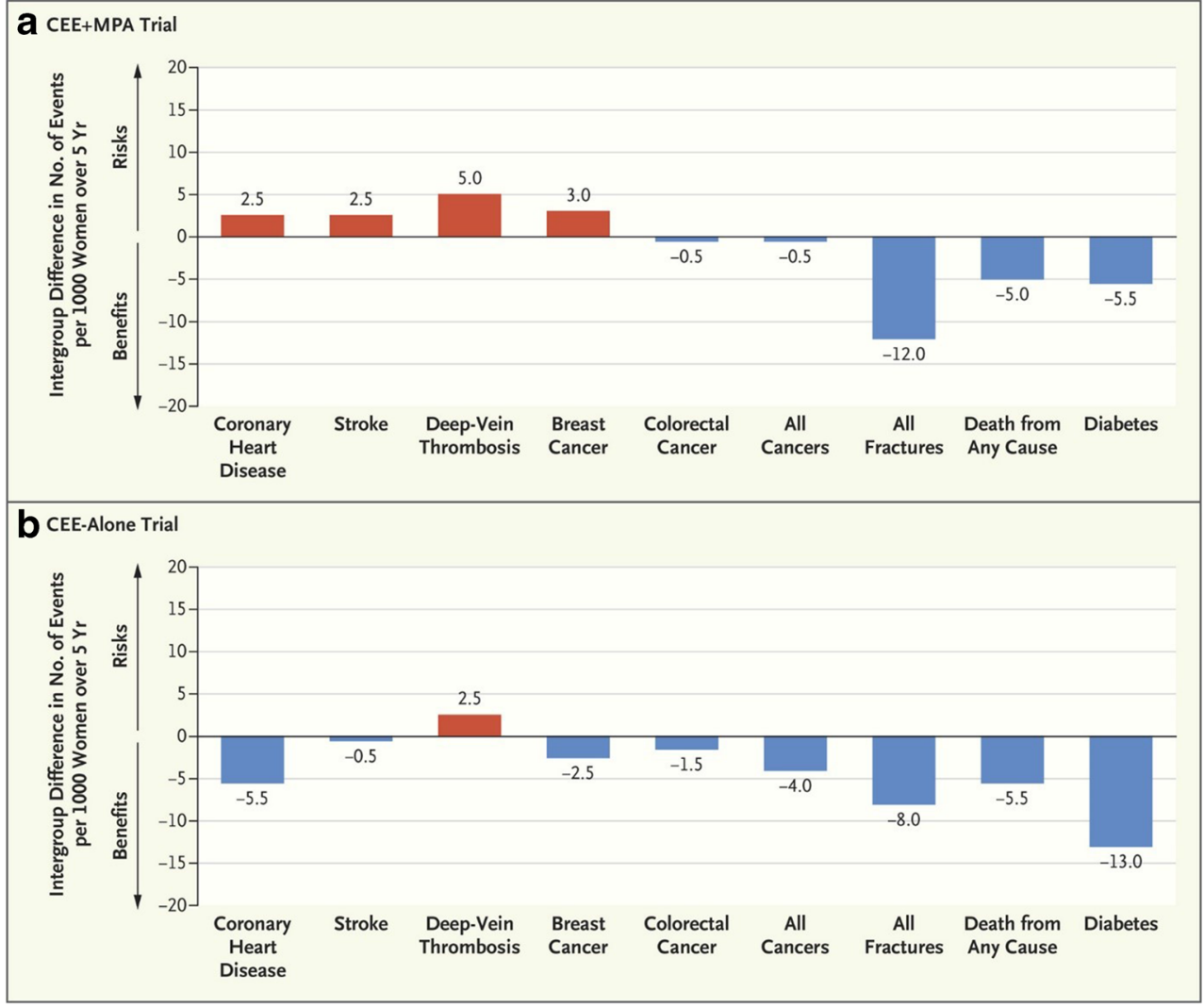

example those who experienced a myocardial infarction in year 1 may have left the trial subsequently), any inferences about longer term treatment with MHT should be made with caution. However, $82 \%$ of those assigned to hormone treatment were taking it at the end of 1 year and $75 \%$ at the end of 3 years, and in fact outcome data were available on $100 \%$ participants. A total of 2321 women (93\% of those surviving) consented to further unblinded follow-up over 2.7 years. The overall RHs for non-fatal myocardial infarction and death due to coronary heart disease, after adjustment for potential confounders and differential use of statins between treatment groups (RH: 0.97 ; 95\% CI: 0.82 to 1.14 ), and in analyses restricted to women who were adherent to randomized treatment assignment (RH: 0.96 ; 95\% CI: 0.77 to 1.19 ) did not provide any evidence of altered CHD risk during the additional follow-up [50]. It is notable that the percent participants who were $>80 \%$ adherent to allocated MHT fell from $81 \%$ at year one to $45 \%$ in year six, and MHT use in the placebo group increased from 0 to $8 \%$ over the same time period, indicating reduced power to detect differences by original treatment allocation.

In the Kronos Early Oestrogen Prevention Study (KEEPS), healthy menopausal women aged 40-58 years who were between 6 and 36 months from the last period and without previous cardiovascular events, were randomized to either oral CEE (0.45 mg/day) or transdermal $17 \beta$-oestradiol (t-E2), $50 \mathrm{mcg} / \mathrm{d}$, each with $200 \mathrm{mg}$ of oral progesterone for 12 days per month or placebo for 48 months [51, 52]. Over the 4-year treatment, amongst 727 women randomized, there was no evidence that hormone therapy, of either type, led to increases in carotid intima media thickness (CIMT) or in coronary artery calcium score, but the trial was not powered to detect differences in clinical outcomes. In this study, neither MHT intervention was associated with alterations to blood pressure, in contrast to oral CEE in WHI, although randomization to t-E2 was associated with decreased insulin resistance. The oral CEE dose in KEEPS (which was lower than that in WHI) was associated with a favourable change in lipid profile in the sense that there was an increase in high-density lipoprotein and decrease in low-density lipoprotein cholesterol; however, there was an associated increase in triglycerides [51, 52].

In the Early versus Late Postmenopausal Treatment with Estradiol randomised trial (ELITE), a total of 643 healthy postmenopausal women were randomly assigned to receive either oral $17 \beta$-oestradiol (1 $\mathrm{mg} /$ day) plus progesterone (45 mg) vaginal gel administered sequentially (once daily for 10 days of each 30-day cycle) for women with a uterus or placebo (plus sequential placebo vaginal gel for women without a uterus) [53]. Randomization was stratified according to time since menopause (less than six years or $\geq 10$ years). Over a median of 5 years, the effect of $17 \beta$-oestradiol with or without progesterone on CIMT progression was different according to commencement early or late after the menopause. The interaction was statistically significant $(p=0.007)$. Thus, 
Table 1 Non-WHI key randomized controlled trials of MHT and main outcomes

\begin{tabular}{|c|c|c|c|c|}
\hline Trial & $N$ & Intervention & Outcomes & Effect \\
\hline $\begin{array}{l}\text { Kronos Early } \\
\text { Oestrogen } \\
\text { Prevention Study } \\
\text { (KEEPS) [51, 52] }\end{array}$ & $\begin{array}{l}\text { Healthy menopausal } \\
\text { women, aged } \\
\begin{array}{l}\text { 40-58 years; } 4 \text { years; } \\
n=727\end{array}\end{array}$ & $\begin{array}{l}\text { Randomized to either oral CEE } \\
(0.45 \mathrm{mg} / \text { day }), \text { or transdermal } \\
17 \beta \text {-oestradiol (t-E2), } 50 \mathrm{mcg} / \mathrm{d}, \\
\text { each with } 200 \mathrm{mg} \text { of oral } \\
\text { progesterone for } 12 \text { days per } \\
\text { month, or placebo for } \\
48 \text { months }\end{array}$ & $\begin{array}{l}\text { Annual change in } \\
\text { coronary artery intima } \\
\text { media thickness } \\
\text { (CIMT); coronary } \\
\text { artery calcium score }\end{array}$ & No differences between groups \\
\hline $\begin{array}{l}\text { Early versus Late } \\
\text { Postmenopausal } \\
\text { Treatment with } \\
\text { Estradiol } \\
\text { randomised trial } \\
\text { (ELITE) [53] }\end{array}$ & $\begin{array}{l}643 \text { healthy } \\
\text { postmenopausal } \\
\text { women; median } \\
5 \text { years }\end{array}$ & $\begin{array}{l}\text { Randomly assigned to receive } \\
\text { either oral } 17 \beta \text {-oestradiol } \\
(1 \mathrm{mg} \text { /day, plus progesterone } \\
(45 \mathrm{mg} \text { ) vaginal gel } \\
\text { administered sequentially (once } \\
\text { daily for } 10 \text { days of each } \\
30 \text {-day cycle, intact uterus) or } \\
\text { placebo (plus sequential placebo } \\
\text { vaginal gel for women without a } \\
\text { uterus) }\end{array}$ & $\begin{array}{l}\text { Primary outcome: Change } \\
\text { in CIMT every six } \\
\text { months. Coronary } \\
\text { atherosclerosis (cardiac } \\
\text { computed tomography) }\end{array}$ & $\begin{array}{l}\text { Early postmenopausal women: } \\
\text { CIMT increased by } 0.0078 \mathrm{~mm} \\
\text { per year in the placebo group } \\
\text { compared with } 0.0044 \mathrm{~mm} \text { per } \\
\text { year in the } 17 \beta \text {-oestradiol group } \\
\text { ( } p=0.008) \\
\text { Late postmenopausal women, } \\
\text { CIMT no difference }(p=0.29) \\
\text { Cardiac CT measurements not } \\
\text { different }\end{array}$ \\
\hline $\begin{array}{l}\text { Danish Osteoporosis } \\
\text { Prevention Study } \\
\text { (DOPS) [54] }\end{array}$ & $\begin{array}{l}1006 \text { healthy recently } \\
\text { postmenopausal } \\
\text { women aged } \\
45-58 \text { years }\end{array}$ & $\begin{array}{l}\text { Randomized to MHT or placebo. } \\
\text { MHT: triphasic oestradiol and } \\
\text { norethisterone acetate (intact } \\
\text { uterus); } 2 \mathrm{mg} / \text { day oestradiol } \\
\text { (hysterectomized) }\end{array}$ & $\begin{array}{l}\text { Primary endpoint: } \\
\text { composite of death, } \\
\text { admission to hospital } \\
\text { for heart failure and } \\
\text { myocardial infarction. }\end{array}$ & $\begin{array}{l}\text { After } 10 \text { years of intervention, HR: } \\
0.48 \text {; } 95 \% \text { CI: } 0.26 \text { to } 0.87 \\
\text { Mortality: HR: } 0.57 ; 95 \% \text { CI: } 0.30 \\
\text { to } 1.08 \\
\text { Breast cancer: HR: } 0.58 ; 95 \% \mathrm{CI} \text { : } \\
\quad 0.27 \text { to } 1.27 \\
\text { DVT: } 2.01 ; 95 \% \mathrm{CI}: 0.18 \text { to } 22.16 \\
\text { Stroke: HR: } 0.77 ; 95 \% \mathrm{CI}: 0.35 \text { to } \\
\quad 1.70 \text {. }\end{array}$ \\
\hline $\begin{array}{l}\text { Heart and } \\
\text { Estrogen/progestin } \\
\text { Replacement } \\
\text { Study (HERS) } \\
\text { Research Trial [49] }\end{array}$ & $\begin{array}{l}2763 \text { women with } \\
\text { coronary disease, } \\
<80 \text { years old (mean } \\
66.7 \text { years), } \\
\text { postmenopausal with } \\
\text { an intact uterus. }\end{array}$ & $\begin{array}{l}\text { Randomized to either } 0.625 \mathrm{mg} \\
\text { CEE plus } 2.5 \mathrm{mg} \text { of MPA or } \\
\text { matched placebo }\end{array}$ & $\begin{array}{l}\text { Primary outcome: } \\
\text { non-fatal myocardial } \\
\text { infarction or coronary } \\
\text { heart disease (CHD) } \\
\text { death }\end{array}$ & $\begin{array}{l}\text { Relative hazard (RH), } 0.99 ; 95 \% \\
\text { CI: } 0.80 \text { to } 1.22 \\
\text { DVT: RH: } 2.89 ; 95 \% \text { CI: } 1.50 \text { to } \\
\text { 5.58 } \\
\text { Gallbladder disease: RH: } 1.38 \text {; } \\
\text { 95\% CI: } 1.00 \text { to } 1.92\end{array}$ \\
\hline $\begin{array}{l}\text { Women's } \\
\text { International Study } \\
\text { of long Duration } \\
\text { Oestrogen after } \\
\text { Menopause } \\
\text { (WISDOM) [55] }\end{array}$ & $\begin{array}{l}6498 \text { women, mean age } \\
62.8 \text { years }\end{array}$ & $\begin{array}{l}2196 \text { women were randomized to } \\
\text { either oestrogen only therapy } \\
\text { (CEE } 0.625 \mathrm{mg} \text { orally daily) or } \\
\text { combined hormone therapy } \\
\text { (CEE plus MPA } 2.5 / 5.0 \mathrm{mg} \\
\text { orally daily) and } 2189 \text { to } \\
\text { matched placebo }\end{array}$ & $\begin{array}{l}\text { Major cardiovascular } \\
\text { events, venous } \\
\text { thromboembolism, } \\
\text { cancer }\end{array}$ & $\begin{array}{l}\text { Major cardiovascular events (7 vs } \\
0 ; p=0.016 \text { ) } \\
\text { Venous thromboembolism HR: } \\
\quad 7.36 ; 95 \% \text { CI: } 2.20 \text { to } 24.60 \\
\text { Cancer: HR: } 0.88 ; 95 \% \text { CI: } 0.49 \text { to } \\
\text { 1.56 } \\
\text { Cerebrovascular events: HR: } 0.73 \text {; } \\
\text { 95\%CI: } 0.37 \text { to } 1.46 \\
\text { Fractures: HR: } 0.69 ; 95 \% \text { CI: } 0.46 \\
\text { to } 1.03 \\
\text { Mortality: HR: } 1.60 ; 95 \% \text { CI: } 0.52 \\
\text { to } 4.89\end{array}$ \\
\hline
\end{tabular}

$C E E$ conjugated equine oestrogen, MPA medroxyprogesterone acetate, CIMT carotid intima media thickness, $H R$ hazard ratio, $D V T$ deep vein thrombosis, $R H$ relative hazard

for those women in the early postmenopausal stratum, the mean CIMT increased by $0.0078 \mathrm{~mm}$ per year in the placebo group compared with $0.0044 \mathrm{~mm}$ per year in the $17 \beta$ oestradiol group $(p=0.008)$. In the late postmenopausal stratum, the rates of CIMT progression were similar between placebo and intervention groups $(p=0.29)$. Measures of coronary artery calcification, total stenosis and plaque from the computed tomography assessments did not differ according to randomization group [53].
The Danish Osteoporosis Prevention Study (DOPS) specifically addressed the issue of treatment with MHT soon after the menopause [54]. In this open-label, randomized controlled trial, 1006 healthy women aged 45-58 years (mean 50 years) who were recently postmenopausal (mean 7 months) were randomized to receive menopausal hormone therapy $(n=502)$ or no treatment $(n=504)$. In the treatment group, women with an intact uterus were treated with triphasic oestradiol and norethisterone acetate; women who 
had undergone hysterectomy received $2 \mathrm{mg}$ oestradiol per day. The trial was stopped after around 11 years as a result of the adverse event signals from the WHI, but the DOPS investigators continued to follow participants for death, cardiovascular and cancer outcomes for up to 16 years. After 10 years of intervention, 16 women in the treatment group experienced the primary composite endpoint (death, admission to hospital for heart failure or myocardial infarction) compared with 33 in the control group (HR: 0.48 ; 95\% CI: 0.26 to 0.87 ) and 15 vs 26 died (HR: 0.57 ; $95 \%$ CI: 0.30 to 1.08 ), consistent with a protective effect of MHT. There was no evidence of an increase in any cancer (intervention vs control: 36 vs 39 ; HR: 0.92 ; $95 \%$ CI: 0.58 to 1.45 ) or in breast cancer (10 vs 17; HR: 0.58 ; 95\%CI: 0.27 to 1.27 ). The HR for deep vein thrombosis ( 2 vs 1 ) was 2.01 ; $95 \%$ CI: 0.18 to 22.16 and for stroke (11 vs 14$)$ was $0.77 ; 95 \%$ CI: 0.35 to 1.70. After 16 years, the reduction in the primary composite outcome was still present and not associated with an increase in any cancer [54]. However, despite the use of hard endpoints, the open-label nature of the trial design does not necessarily warrant the same level of confidence as would be associated with a truly double-blind structure.

The Women's International Study of long Duration Oestrogen after Menopause (WISDOM) trial was stopped early after a median of 11.9 months recruitment as a result of the findings from the WHI [55]. A total of 6498 women had been enrolled, with a mean age similar to that of women in the WHI (62.8 years). A total of 2196 women were randomized to either oestrogen only therapy (CEE $0.625 \mathrm{mg}$ orally daily) or combined hormone therapy (CEE plus MPA 2.5/5.0 mg orally daily) and 2189 to matched placebo. Consistent with findings from the WHI, there was a significant increase in the number of major cardiovascular events ( 7 vs 0 ; HR $p=0.016$ ) and venous thromboembolism (22 vs 3; HR: 7.36; 95\% CI: 2.20 to 24.60 ) in the combined HT group vs placebo. There were no statistically significant differences in numbers of breast or other cancers (22 vs 25 ; HR: 0.88 ; $95 \%$ CI: 0.49 to 1.56 ), cerebrovascular events (14 vs 19 ; HR: 0.73 ; $95 \%$ CI: 0.37 to 1.46 ), fractures (40 vs 58 ; HR: $0.69 ; 95 \%$ CI: 0.46 to 1.03 ) and overall deaths ( 8 v 5; HR: 1.60 ; $95 \%$ CI: 0.52 to 4.89 ). Comparison of combined hormone therapy $(n=815)$ versus oestrogen therapy ( $n=826)$ outcomes revealed no significant differences; the numbers of events were relatively low compared with WHI.

Finally a meta-analysis of 23 MHT trials, including 39,049 participants followed for 191,340 patient-years, showed that hormone therapy appeared to significantly reduce CHD events in younger (mean time postmenopause < 10 years or age $<60$ years) women [Odds ratio (OR): 0.68 ; 95\%CI: 0.48 to 0.96 ], but not in older women (OR: 1.03 ; 95\% CI: 0.91 to 1.16 ). In older women, hormone therapy increased CHD events in the first year (OR: 1.47; 95\%CI: 1.12 to 1.92 ) then reduced events after 2 years (OR: 0.79 ; 0.67 to 0.93 ) [56].

\section{How might MHT differentially influence ischaemic cardiovascular outcomes by age?}

The concept that oestrogen might differentially influence cardiovascular risk depending upon time since menopause, or chronological age, originated in animal studies of nonhuman primates. Thus, in cynomolgus monkeys, conjugated oestrogens with or without MPA were not associated with any changes in coronary artery plaques when the hormone therapy was commenced at 2 years (equivalent to around 6 human years) after oophorectomy and in the presence of established atherosclerosis. In contrast, this intervention reduced plaque size by $70 \%$ when initiated immediately following oophorectomy in the early stages of atherosclerosis [57]. These findings are consistent with the results of the KEEPS, ELITE and DOPS trials described above and of human imaging trials in participants with significant coronary lesions at baseline in which oestrogen appeared not to slow the rate of arterial narrowing [58-61]. In contrast, a protective effect of oestrogen on coronary artery atherosclerosis was observed in a further imaging trial in which severe coronary artery lesions were not a criterion for enrolment [62]. These findings suggest that oestrogen might have differential effects on the progression of atherosclerotic disease and/or thrombotic events depending upon the degree of baseline atherosclerotic disease. There is evidence that oestrogen may increase nitric oxide synthesis and thus vasodilation and potentially decrease inflammatory cell adhesion and thus slow the progression of atherosclerotic plaques, in the setting of healthy arteries, which of course are more likely in younger patients closer to the menopause. In older women with substantial atherosclerotic plaque, oestrogen receptors may become less responsive and there is some evidence that oestrogen may adversely affect established atherosclerotic plaques, rendering them more susceptible to rupture and subsequent thrombotic occlusion of the blood vessel [63]. Findings from WHI in relation to lipid status are consistent with these hypotheses. Thus, CEE with or without MPA was associated with a $40 \%$ lower risk of incident coronary heart disease amongst women with a favourable LDL/HDL ratio, but risk of these outcomes was greater in women with an adverse LDL/HDL ratio at baseline [64]. Furthermore, the risk of coronary heart disease outcomes associated with hormone therapy was more than double in those with metabolic syndrome compared to those without [65]. Again, within the WHI, measurements of coronary artery calcium amongst women aged 50-59 years were lower amongst women assigned to oestrogen alone than amongst those assigned to placebo [66]. As with all analyses of subsets within the overall randomized trial population, such investigation should be interpreted with caution given their secondary nature and that randomization of covariates may not be preserved. 


\section{Use of MHT for maintenance of bone health}

\section{Health economics}

The cost-effectiveness of MHT has been examined in relation to the treatment of menopausal symptoms and for fracture prevention in asymptomatic women but who are at high risk of a fragility fracture. Zethraeus et al. incorporated the emerging data on efficacy and side effects from WHI into an individual state transition model of 50- to 60-year-old women with menopausal symptoms using a societal perspective in Sweden [67]. The group undertook a similar analysis for a population based in the UK using a Markov cohort simulation model in women aged 50 years with clinical effectiveness and side effects informed by the WHI [68]. In both of these studies, together with an analysis based on the US population [69], there was evidence of costeffectiveness. The severity of menopausal symptoms was the most and only one important determinant of cost-effectiveness, but MHT remained cost-effective even where symptoms were mild or the effects on symptom relief was small [68]. A further analysis focused on women at high risk of fracture, but no menopausal symptoms, in Sweden, the US and the UK, with the clinical effects again based on the findings from the WHI [70]. The state transition model had a lifetime horizon with disease states across fracture, cancer and cardiovascular outcomes. The results demonstrated that MHT was cost-effective compared with no treatment for the majority of subgroups of hysterectomized women. In contrast, for women with an intact uterus without a prior fracture, the evidence for cost-effectiveness was less clear. In this analysis, fracture risk was the single most important determinant of the cost-effectiveness findings [70]. Thus, when fracture risk was taken into account rather than menopausal symptoms, use of MHT was cost-effective in women who had had a hysterectomy irrespective of prior fracture status. In contrast, amongst women with an intact uterus, opposed MHT was cost-effective only in those with a prior vertebral fracture. Overall then, these data favour the use of MHT for prevention of menopausal symptoms but do not clearly support a specific role in fracture prevention, particularly in low fracture risk individuals. A further caveat is that the analyses do not account for time since menopause, which would be expected to improve cost-effectiveness, and it is clearly important not to automatically conflate costeffectiveness with clinical appropriateness.

\section{Existing guidelines}

The notion that MHT might be an appropriate first line therapy for the maintenance of bone health in recently postmenopausal women is consistent with that proposed in several current guidelines internationally. Thus the European Menopause and Andropause Society (EMAS) states that "Administration of systemic MHT has a favourable risk-benefit profile for women under the age of 60 years or within 10 years after menopause for menopausal symptoms and osteoporosis" [71]. The North American Menopause Society (NAMS) acknowledges the effect of age post menopause on the risk-benefit landscape and explicitly cites skeletal health as a consideration: "For women aged younger than 60 years or who are within 10 years of menopause onset and have no contraindications, the benefitrisk ratio is most favourable for treatment of bothersome vasomotor symptoms and for those at elevated risk for bone loss or fracture." [72] This approach is also incorporated into guidance from the International Menopause Society (IMS) [73]. The American Association of Clinical Endocrinologists recommend that "MHT should be used for the prevention and treatment of osteoporosis within the context of the overall benefit-versusrisk analysis of each patient" but also that "MHT should be used in the lowest dose and for the shortest period necessary to control menopausal symptoms" [74]. In contrast, the American College of Obstetricians and Gynaecologists focuses on menopausal symptoms [75], and lowest dose, shortest time paradigm (to adequately control menopausal symptoms), with the US Endocrine Society suggesting that there is no support for using MHT to prevent coronary heart disease, breast cancer or dementia, but with ambivalence towards fracture prevention [76]. A 2016 Global Consensus Statement, endorsed by IMS, NAMS, The Endocrine Society, EMAS, The Asia Pacific Menopause Federation, The International Osteoporosis Foundation and The Federation of Latin American Menopause Societies, explicitly proposed that "MHT...can be initiated in postmenopausal women at risk of fracture or osteoporosis before the age of 60 years or within 10 years after menopause" but that "Initiation of MHT after the age of 60 years for the indication of fracture prevention is considered second-line therapy and requires individually calculated benefit/risk, compared to other approved drugs. If MHT is elected, the lowest effective dose should be used." [77] Finally clinical guidance from the UK National Institute for Health and Care Excellence (NICE) focuses on the use of MHT for postmenopausal symptoms and suggests that under the age of 60 years, the risks of cardiovascular disease are negligible for oestrogen only MHT and that there is little or no increased risk of coronary heart disease with combined MHT. Again, an individualized approach accommodating baseline cardiovascular risk is recommended, together with consideration of other factors such as history of breast cancer and thromboembolic disease [16].

\section{Clinical approach}

Osteoporosis is now a well-defined morbidity, with associated diagnostic criteria, methods of detection and, importantly, a range of effective treatment modalities [22]. Approaches to detection and assessment of individuals at low, high and very high risk of experiencing an osteoporotic fracture have been recently set out in detail by the European Society for Clinical and Economic Aspects of Osteoporosis, Osteoarthritis and 
Musculoskeletal Diseases (ESCEO) and the International Osteoporosis Foundation (IOF) [5], building on the 2019 European Guidance for Assessment and Treatment of Postmenopausal Osteoporosis from the same societies [4]. The stratification of management approach according to risk level accommodates the nuances of the range of medications currently available, encompassing interventions including calcium and vitamin D supplementation all the way through bisphosphonates up to anabolic therapies. Within this framework, MHT is considered as a potential preventative intervention as the initial part of a longer term management strategy for those postmenopausal women found to be at low risk of fragility fracture over the next 10 years, using the FRAX® algorithm, but who of course may have a much greater remaining lifetime risk (Fig. 2) [5]. In this setting, a specific bone therapy (for example a bisphosphonate) may not be appropriate, and the question is, on the one hand, whether the use of MHT should be specifically indicated for the maintenance of bone health and prevention of fractures or, on the other hand, whether fracture risk reduction should be viewed as an additional benefit from a medication used for treatment of menopausal symptoms. Ultimately, this depends on the individual balance of benefits versus risks: the current literature suggests robust anti-fracture efficacy of MHT in patients unselected for low BMD, regardless of concomitant use with progestogens, but with little evidence for persisting benefits following cessation of therapy. The risks appear to vary according to age/time of use, with potential cardiovascular benefits for unopposed oestrogen (in hysterectomized women) used within 10 years after the menopause in WHI, and null effects for opposed oestrogen in KEEPS, but potential cardiovascular benefits when initiated close to the menopause in the ELITE and DOPS Trials. Other side effects such as deep-vein thrombosis, stroke and gall bladder disease are raised to a greater or lesser extent according to use of opposed or unopposed oestrogen, dose and route of administration, and should all be considered. Breast cancer remains a key consideration with combined MHT $[16,24]$. Although there is clearly concern with regard to side effects of MHT, these must be understood in the context, firstly, of the absolute risks of such events in the menopausal population, and secondly, of the benefitrisk balance for other medications used in osteoporosis treatment. For example, a UK 50-year-old woman with no cardiovascular risk factors has a $2 \%$ chance of experiencing a myocardial infarction or stroke over the next 10 years (QRISK: https://qrisk.org/three/). In this context, a 34\% CHD uplift (as noted in WHI for a women with an intact uterus treated with combined MHT [8]) will not be particularly clinically significant (final absolute risk 2.68\%). Whilst the lifetime impact of, for example, a 5-year course of MHT from the age of menopause is not known, when absolute risks are considered, the use of MHT in menopausal women at low baseline cardiovascular risk seems a reasonable option. In terms of other medications used for bone protection, raloxifene is also associated with an increased risk of thromboembolic disease, at the same order of magnitude; bisphosphonates and denosumab have been associated with rare but serious side effects such as osteonecrosis of the jaw and atypical femoral
Fig. 2 Treatment options at different levels of baseline fracture risk (reused with permission from [5]). Note that risk categories do not specifically correspond to age or menopause status. LOEP local osteoenhancement procedure
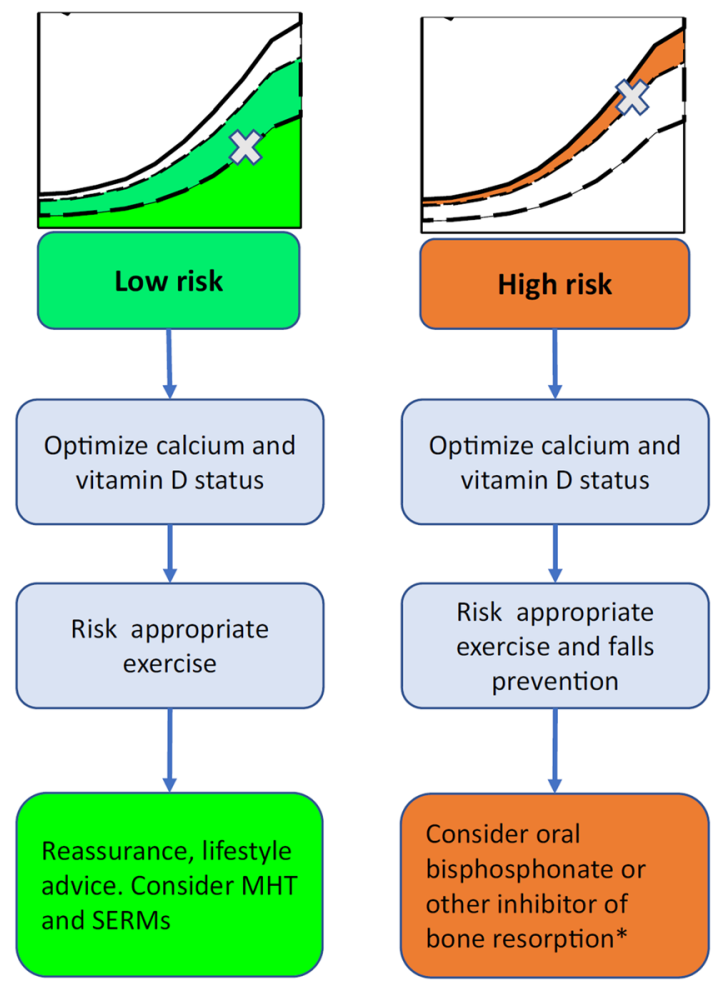
fractures; intravenous bisphosphonates and denosumab may lead to symptomatic hypocalcaemia; romosozumab was associated with increased risk of cardiovascular side effects in one of its key trials $[3,78]$. Finally, strontium ranelate, for which the licence was restricted by the European Medicines Authority on the basis of a signal for increased risk of myocardial infarction and subsequently voluntarily withdrawn (although now back on the market as a generic preparation), is also associated with increased risk of deep vein thrombosis [79]. This wider context, taken with the logistic issues and risks of oesophageal ulceration associated with improper use of oral bisphosphonates, should lead to a more nuanced appraisal of the benefit-risk balance for MHT. Taking all the evidence together then, MHT is most strongly supported for the primary indication of prevention of menopausal symptoms. Clearly in this context, it may also be viewed as having the added benefit of preventing bone loss and reducing fracture risk. The benefit-risk balance for a primary indication of fracture prevention is less clearly defined, and we suggest that in recently postmenopausal women for whom maintenance of skeletal health is a clinical priority, whilst MHT might be considered in those at low risk of cardiovascular disease, thromboembolic disease and breast cancer as a first line therapy, ultimately further research of MHT in the context of a long term osteoporosis management strategy is required. The detailed exposition of the clinical assessment of menopausal symptoms and their specific treatment (with associated risks) is beyond the scope of this article, but is very comprehensively summarized in the various sets of guidance from international and national bodies described in the preceding section.

\section{Conclusion}

The evidence surrounding the use of MHT is complex and spans a wide range of often conflicting findings from observational studies and randomized trials. The field has been beset with highly publicized controversies, which have seen MHT use decline sharply following initial WHI results, with something of a move towards rehabilitation of this intervention through subsequent analyses. MHT has a clear role in the treatment of menopausal symptoms and for many menopausal women, use of MHT commenced at the time of, or shortly after, menopause, under the age of 60 years, may be considered as an option, in this context, to achieve the additional benefit of maintenance of bone health where specific bone active medications are not warranted. Risk assessment should be individualized, taking into account baseline risk of breast cancer, together with that of cardiovascular, cerebrovascular and thromboembolic events, in addition to fracture risk. Such assessment should be undertaken in the context of menopausal symptoms and detailed discussion with the patient to reach an optimal understanding of the benefit-risk balance. Nuances such as the distinction in associations with outcome according to whether oestrogen is opposed or unopposed, and thus the relevance of prior hysterectomy and the use of different oestrogens and progestogens, doses and routes of administration, are all important considerations. Clearly, it is important to use preparations that have documented anti-fracture efficacy if bone protection is desired, and the approach chosen should be tailored to the individual benefit-risk balance. Used in this way, we suggest that the evidence supports the consideration of MHT as a means of achieving bone protection and fracture prevention in the context of a primary indication for menopausal symptom treatment, in recently postmenopausal women at low baseline risk of cardiovascular disease, cerebrovascular disease, thromboembolic disease and breast cancer.

Funding information The European Society for Clinical and Economic Aspects of Osteoporosis, Osteoarthritis and Musculoskeletal Diseases Working Group was entirely funded by the European Society for Clinical and Economic Aspects of Osteoporosis, Osteoarthritis and Musculoskeletal Diseases. The European Society for Clinical and Economic Aspects of Osteoporosis, Osteoarthritis and Musculoskeletal Diseases receives Unrestricted Educational Grants to support its educational and scientific activities from non-governmental organizations, notfor-profit organizations and non-commercial or corporate partners. The choice of topics, participants, content and agenda of the Working Groups as well as the writing, editing, submission and reviewing of the manuscript are the sole responsibility of the European Society for Clinical and Economic Aspects of Osteoporosis, Osteoarthritis and Musculoskeletal Diseases, without any influence from third parties.

\section{Compliance with ethical standards}

Conflicts of interest N. Al-Daghri has no disclosures. M. AubertinLeheudre has no disclosures. M-L. Brandi reports honoraria from Amgen, Bruno Farmaceutici, Calcilytix and Kyowa Kirin; academic grants and/or speaker fees from Abiogen, Alexion, Amgen, Bruno Farmaceutici, Eli Lilly, Kyowa Kirin, MSD, NPS, Servier, Shire and SPA; and consultancy fees from Alexion, Bruno Farmaceutici, Kyowa Kirin, Servier and Shire outside the scope of the submitted work. A. Cano reports consultancy, honoraria and lecture fees from Theramex and Italfarmaco outside the scope of the submitted work. P. Collins reports consultancy, lecture fees and honoraria from Eli Lilly, Abbott, Novo Nordisk and Bayer outside the scope of the submitted work. C. Cooper reports consultancy, lecture fees and honoraria from AMGEN, GSK, Alliance for Better Bone Health, MSD, Eli Lilly, Pfizer, Novartis, Servier, Medtronic and Roche outside the scope of the submitted work. A. Genazzani has no disclosures. N. Harvey reports consultancy, lecture fees and honoraria from Alliance for Better Bone Health, AMGEN, MSD, Eli Lilly, Servier, Shire, UCB, Kyowa Kirin, Consilient Healthcare, Radius Health and Internis Pharma outside the scope of the submitted work. T. Hillard reports lecture fees and honoraria from Shionogi, Novo Nordisk and Theramex outside the scope of the submitted work. J. Kanis reports grants from UCB, grants from Amgen and grants from Radius Health outside the submitted work, and Dr. Kanis is a member of the National Osteoporosis Guideline Group (NOGG) and the principal architect of FRAX but derives no financial benefit. J-M. Kaufman is board member (treasurer) of ESCEO. I. Lambrinoudaki has no disclosures. A. Laslop has no disclosures. E. McCloskey reports consultant/advisor/speaker fees or research funding from Agnovos, Amgen, AstraZeneca, Consilient Healthcare, Fresenius Kabi, GSK, Hologic, I3 
Innovus, Internis, Lilly, Merck, MRC, Novartis, Pfizer, Roche, SanofiAventis, Servier, Synexus, UCB, Unilever, Versus Arthritis and Warner Chilcott outside the scope of the submitted work. S. Palacios has received consultancy, lecture fees, honoraria and grants from Serelys, Pfizer, Amgen, Gedeon Ritcher, Exeltis, Bayer Schering, MSD, Procare Health, Mylan and Shionogi outside the scope of the submitted work. D. Prieto-Alhambra's research group reports research grants from Amgen, Servier and UCB; speaker tuition fees and advisory or consultancy fees (all paid to his department) from Amgen and UCB outside the scope of the submitted work. J-Y. Reginster reports consulting fees or paid advisory boards from IBSA-Genevrier, Mylan, Radius Health and Pierre Fabre; lecture fees when speaking at the invitation of sponsor from IBSA-Genevrier, Mylan, CNIEL and Dairy Research Council (DRC); and grant support from Industry (All through Institution) from IBSAGenevrier, Mylan, CNIEL and Radius Health outside the scope of the submitted work. R. Rizzoli reports fees for advisory board or lectures from Abiogen, Amgen, CNIEL, Danone, Echolight, Effryx, EMF, Mithra, Mylan, Nestlé, ObsEva, Radius Health, Rejuvenate, Sandoz and Theramex outside the scope of the submitted work. G. Rosano has no disclosures. S. Rozenberg reports consultancy, lecture fees, honoraria and grants from Mylan, Abbott, Gedeon-Richter, UCB and Amgen outside the scope of the submitted work. F. Trémollieres reports lecture and/ or consultancy fees from Amgen, Arrow, Lilly France and Theramex and non-financial support for meeting from Besins Healthcare France outside the scope of the submitted work.

Consents and ethics approval This review article reports previously published findings and does not include any new research.

Open Access This article is licensed under a Creative Commons Attribution-NonCommercial 4.0 International License, which permits any non-commercial use, sharing, adaptation, distribution and reproduction in any medium or format, as long as you give appropriate credit to the original author(s) and the source, provide a link to the Creative Commons licence, and indicate if changes were made. The images or other third party material in this article are included in the article's Creative Commons licence, unless indicated otherwise in a credit line to the material. If material is not included in the article's Creative Commons licence and your intended use is not permitted by statutory regulation or exceeds the permitted use, you will need to obtain permission directly from the copyright holder. To view a copy of this licence, visit http:// creativecommons.org/licenses/by-nc/4.0/.

\section{References}

1. Harvey NCW, McCloskey EV, Rizzoli R, Kanis JA, Cooper C, Reginster J-Y (2019) Osteoporosis: treatment gaps and health economics. In: Huhtaniemi I, Martini L (eds) Encyclopedia of endocrine diseases, 2nd edn. Academic Press, Oxford, pp 288-295

2. Harvey N, Dennison E, Cooper C (2010) Osteoporosis: impact on health and economics. Nat Rev Rheumatol 6:99-105

3. Curtis EM, McClung M, Compston JE (2018) Therapeutic approaches to bone protection in adulthood. In: Harvey NC, Cooper C (eds) Osteoporosis: a lifecourse epidemiology approach to skeletal health. CRC Press, Boca Raton, pp 177-192

4. Kanis JA, Cooper C, Rizzoli R, Reginster JY (2019) European guidance for the diagnosis and management of osteoporosis in postmenopausal women. Osteoporos Int 30:3-44

5. Kanis JA, Harvey NC, McCloskey E et al (2019) Algorithm for the management of patients at low, high and very high risk of osteoporotic fractures. Osteoporos Int 31(1):1-12
6. Tremollieres F (2019) Assessment and hormonal management of osteoporosis. Climacteric 22:122-126

7. Chester RC, Kling JM, Manson JE (2018) What the Women's Health Initiative has taught us about menopausal hormone therapy. Clin Cardiol 41:247-252

8. Bassuk SS, Manson JE (2016) The timing hypothesis: do coronary risks of menopausal hormone therapy vary by age or time since menopause onset? Metabolism 65:794-803

9. Manson JE, Kaunitz AM (2016) Menopause management-getting clinical care back on track. N Engl J Med 374:803-806

10. Rossouw JE, Anderson GL, Prentice RL, LaCroix A, Kooperberg C, Stefanick ML, Jackson RD, Beresford SA, Howard BV, Johnson KC, Kotchen JM, Ockene J, Writing Group for the Women's Health Initiative Investigators (2002) Risks and benefits of estrogen plus progestin in healthy postmenopausal women: principal results from the Women's Health Initiative randomized controlled trial. JAMA 288:321-333

11. Hernan MA, Alonso A, Logan R, Grodstein F, Michels KB, Willett WC, Manson JE, Robins JM (2008) Observational studies analyzed like randomized experiments: an application to postmenopausal hormone therapy and coronary heart disease. Epidemiology 19: 766-779

12. Hamoda H (2017) The British Menopause Society and Women's Health Concern recommendations on the management of women with premature ovarian insufficiency. Post Reproductive Health 23: $22-35$

13. Burger HG (1996) The menopausal transition. Baillieres Clin Obstet Gynaecol 10:347-359

14. Harlow SD, Gass M, Hall JE, Lobo R, Maki P, Rebar RW, Sherman S, Sluss PM, de Villiers TJ (2012) Executive summary of the stages of reproductive aging workshop +10 : addressing the unfinished agenda of staging reproductive aging. J Clin Endocrinol Metab 97:1159-1168

15. Labrie F (2015) All sex steroids are made intracellularly in peripheral tissues by the mechanisms of intracrinology after menopause. $\mathrm{J}$ Steroid Biochem Mol Biol 145:133-138

16. (2015) Menopause: diagnosis and management; NG23. National Institute for Health and Care Excellence, London

17. Albright F (1947) Osteoporosis. Ann Intern Med 27:861-882

18. Curtis EM, Moon RJ, Dennison EM, Harvey NC, Cooper C (2015) Recent advances in the pathogenesis and treatment of osteoporosis. Clinical medicine (London, England) 15(Suppl 6):s92-s96

19. Seeman E (2004) Estrogen, androgen, and the pathogenesis of bone fragility in women and men. Curr Osteoporosis Rep 2:90-96

20. Stein EM, Liu XS, Nickolas TL, Cohen A, McMahon DJ, Zhou B, Zhang C, Kamanda-Kosseh M, Cosman F, Nieves J, Guo XE, Shane E (2012) Microarchitectural abnormalities are more severe in postmenopausal women with vertebral compared to nonvertebral fractures. J Clin Endocrinol Metab 97:E1918-E1926

21. Lee SJ, Kanis JA (1993) An association between osteoporosis and premenstrual symptoms and postmenopausal symptoms. Bone Miner 24:127-134

22. Curtis EM, Harvey NC, Cooper C (2018) The burden of osteoporosis. In: Harvey NC, Cooper C (eds) Osteoporosis: a lifecourse epidemiology approach to skeletal health. CRC Press, Boca Raton, pp 1-20

23. Curtis EM, van der Velde R, Moon RJ, van den Bergh JP, Geusens P, de Vries F, van Staa TP, Cooper C, Harvey NC (2016) Epidemiology of fractures in the United Kingdom 1988-2012: variation with age, sex, geography, ethnicity and socioeconomic status. Bone 87:19-26

24. Rozenberg S, Vandromme J, Antoine C (2013) Postmenopausal hormone therapy: risks and benefits. Nat Rev Endocrinol 9:216 227

25. Crandall CJ, Hovey KM, Andrews C, Cauley JA, Stefanick M, Shufelt C, Prentice RL, Kaunitz AM, Eaton C, Wactawski-Wende 
J, Manson JAE (2017) Comparison of clinical outcomes among users of oral and transdermal estrogen therapy in the Women's Health Initiative Observational Study. Menopause 24:1145-1153

26. Crandall CJ, Hovey KM, Andrews CA, Chlebowski RT, Stefanick ML, Lane DS, Shifren J, Chen C, Kaunitz AM, Cauley JA, Manson JAE (2018) Breast cancer, endometrial cancer, and cardiovascular events in participants who used vaginal estrogen in the Women's Health Initiative Observational Study. Menopause 25:11-20

27. Cummings SR, Ettinger B, Delmas PD, Kenemans P, Stathopoulos V, Verweij P, Mol-Arts M, Kloosterboer L, Mosca L, Christiansen C, Bilezikian J, Kerzberg EM, Johnson S, Zanchetta J, Grobbee DE, Seifert W, Eastell R, LIFT Trial Investigators (2008) The effects of tibolone in older postmenopausal women. N Engl J Med 359:697-708

28. Riis BJ, Johansen J, Christiansen C (1988) Continuous oestrogenprogestogen treatment and bone metabolism in post-menopausal women. Maturitas 10:51-58

29. Riis BJ, Jensen J, Christiansen C (1987) Cyproterone acetate, an alternative gestagen in postmenopausal oestrogen/gestagen therapy. Clin Endocrinol 26:327-334

30. Riis BJ, Thomsen K, Strom V, Christiansen C (1987) The effect of percutaneous estradiol and natural progesterone on postmenopausal bone loss. Am J Obstet Gynecol 156:61-65

31. Lufkin EG, Wahner HW, O'Fallon WM, Hodgson SF, Kotowicz MA, Lane AW, Judd HL, Caplan RH, Riggs BL (1992) Treatment of postmenopausal osteoporosis with transdermal estrogen. Ann Intern Med 117:1-9

32. (1996) Effects of hormone therapy on bone mineral density: results from the postmenopausal estrogen/progestin interventions (PEPI) trial. The Writing Group for the PEPI [see comments]. JAMA 276:1389-1396

33. Cauley JA, Robbins J, Chen Z, Cummings SR, Jackson RD, LaCroix A, LeBoff M, Lewis CE, McGowan J, Neuner J, Pettinger M, Stefanick ML, Wactawski-Wende J, Watts NB, Women's Health Initiative Investigators (2003) Effects of estrogen plus progestin on risk of fracture and bone mineral density: the Women's Health Initiative randomized trial. JAMA 290:17291738

34. Bagger YZ, Tanko LB, Alexandersen P, Hansen HB, Mollgaard A, Ravn P, Qvist P, Kanis JA, Christiansen C (2004) Two to three years of hormone replacement treatment in healthy women have long-term preventive effects on bone mass and osteoporotic fractures: the PERF study. Bone 34:728-735

35. Lindsay R, Hart DM, MacLean A, Clark AC, Kraszewski A, Garwood J (1978) Bone response to termination of oestrogen treatment. Lancet 1:1325-1327

36. Yates J, Barrett-Connor E, Barlas S, Chen YT, Miller PD, Siris ES (2004) Rapid loss of hip fracture protection after estrogen cessation: evidence from the National Osteoporosis Risk Assessment. Obstet Gynecol 103:440-446

37. Karim R, Dell RM, Greene DF, Mack WJ, Gallagher JC, Hodis HN (2011) Hip fracture in postmenopausal women after cessation of hormone therapy: results from a prospective study in a large health management organization. Menopause 18:1172-1177

38. Heiss G, Wallace R, Anderson GL, Aragaki A, Beresford SA, Brzyski R, Chlebowski RT, Gass M, LaCroix A, Manson JE, Prentice RL, Rossouw J, Stefanick ML, WHI Investigators (2008) Health risks and benefits 3 years after stopping randomized treatment with estrogen and progestin. JAMA 299:1036-1045

39. LaCroix AZ, Chlebowski RT, Manson JE, Aragaki AK, Johnson KC, Martin L, Margolis KL, Stefanick ML, Brzyski R, Curb JD, Howard BV, Lewis CE, Wactawski-Wende J, WHI Investigators (2011) Health outcomes after stopping conjugated equine estrogens among postmenopausal women with prior hysterectomy: a randomized controlled trial. JAMA 305:1305-1314
40. Manson JE, Chlebowski RT, Stefanick ML et al (2013) Menopausal hormone therapy and health outcomes during the intervention and extended poststopping phases of the Women's Health Initiative randomized trials. JAMA 310:1353-1368

41. Watts NB, Cauley JA, Jackson RD, LaCroix A, Lewis CE, Manson JE, Neuner JM, Phillips LS, Stefanick ML, Wactawski-Wende J, Crandall C, Women's Health Initiative Investigators (2017) No increase in fractures after stopping hormone therapy: results from the Women's Health Initiative. J Clin Endocrinol Metab 102:302308

42. Robbins JA, Aragaki A, Crandall CJ, Manson JAE, Carbone L, Jackson R, Lewis CE, Johnson KC, Sarto G, Stefanick ML, Wactawski-Wende J (2014) Women's Health Initiative clinical trials: interaction of calcium and vitamin D with hormone therapy. Menopause 21:116-123

43. Zhu L, Jiang X, Sun Y, Shu W (2016) Effect of hormone therapy on the risk of bone fractures: a systematic review and meta-analysis of randomized controlled trials. Menopause 23:461-470

44. Levin VA, Jiang X, Kagan R (2018) Estrogen therapy for osteoporosis in the modern era. Osteoporos Int 29:1049-1055

45. Sprague BL, Trentham-Dietz A, Cronin KA (2012) A sustained decline in postmenopausal hormone use: results from the National Health and Nutrition Examination Survey, 1999-2010. Obstet Gynecol 120:595-603

46. Manson JE, Hsia J, Johnson KC, Rossouw JE, Assaf AR, Lasser NL, Trevisan M, Black HR, Heckbert SR, Detrano R, Strickland OL, Wong ND, Crouse JR, Stein E, Cushman M, Women's Health Initiative Investigators (2003) Estrogen plus progestin and the risk of coronary heart disease. N Engl J Med 349:523-534

47. Mikkola TS, Tuomikoski P, Lyytinen H, Korhonen P, Hoti F, Vattulainen P, Gissler M, Ylikorkala O (2015) Increased cardiovascular mortality risk in women discontinuing postmenopausal hormone therapy. J Clin Endocrinol Metab 100:4588-4594

48. Venetkoski M, Savolainen-Peltonen H, Rahkola-Soisalo P, Hoti F, Vattulainen P, Gissler M, Ylikorkala O, Mikkola TS (2018) Increased cardiac and stroke death risk in the first year after discontinuation of postmenopausal hormone therapy. Menopause 25:375379

49. Hulley S, Grady D, Bush T, Furberg C, Herrington D, Riggs B, Vittinghoff E (1998) Randomized trial of estrogen plus progestin for secondary prevention of coronary heart disease in postmenopausal women. Heart and Estrogen/progestin Replacement Study (HERS) Research Group. JAMA 280:605-613

50. Grady D, Herrington D, Bittner V, Blumenthal R, Davidson M, Hlatky M, Hsia J, Hulley S, Herd A, Khan S, Newby LK, Waters D, Vittinghoff E, Wenger N, HERS Research Group (2002) Cardiovascular disease outcomes during 6.8 years of hormone therapy: heart and estrogen/progestin replacement study follow-up (HERS II). JAMA 288:49-57

51. Harman SM, Black DM, Naftolin F, Brinton EA, Budoff MJ, Cedars MI, Hopkins PN, Lobo RA, Manson JAE, Merriam GR, Miller VM, Neal-Perry G, Santoro N, Taylor HS, Vittinghoff E, Yan M, Hodis HN (2014) Arterial imaging outcomes and cardiovascular risk factors in recently menopausal women: a randomized trial. Ann Intern Med 161:249-260

52. Miller VM, Black DM, Brinton EA, Budoff MJ, Cedars MI, Hodis HN, Lobo RA, Manson JE, Merriam GR, Naftolin F, Santoro N, Taylor HS, Harman SM (2009) Using basic science to design a clinical trial: baseline characteristics of women enrolled in the Kronos Early Estrogen Prevention Study (KEEPS). J Cardiovasc Transl Res 2:228-239

53. Hodis HN, Mack WJ, Henderson VW, Shoupe D, Budoff MJ, Hwang-Levine J, Li Y, Feng M, Dustin L, Kono N, Stanczyk FZ, Selzer RH, Azen SP, ELITE Research Group (2016) Vascular effects of early versus late postmenopausal treatment with estradiol. N Engl J Med 374:1221-1231 
54. Schierbeck LL, Rejnmark L, Tofteng CL, Stilgren L, Eiken P, Mosekilde L, Kober L, Jensen JE (2012) Effect of hormone replacement therapy on cardiovascular events in recently postmenopausal women: randomised trial. BMJ 345:e6409

55. Vickers MR, MacLennan AH, Lawton B, Ford D, Martin J, Meredith SK, DeStavola B, Rose S, Dowell A, Wilkes HC, Darbyshire JH, Meade TW, WISDOM group (2007) Main morbidities recorded in the women's international study of long duration oestrogen after menopause (WISDOM): a randomised controlled trial of hormone replacement therapy in postmenopausal women. BMJ 335:239

56. Salpeter SR, Walsh JM, Greyber E, Salpeter EE (2006) Brief report: coronary heart disease events associated with hormone therapy in younger and older women. A meta-analysis. J Gen Intern Med 21: 363-366

57. Mikkola TS, Clarkson TB (2002) Estrogen replacement therapy, atherosclerosis, and vascular function. Cardiovasc Res 53:605-619

58. Herrington DM, Reboussin DM, Brosnihan KB, Sharp PC, Shumaker SA, Snyder TE, Furberg CD, Kowalchuk GJ, Stuckey TD, Rogers WJ, Givens DH, Waters D (2000) Effects of estrogen replacement on the progression of coronary-artery atherosclerosis. N Engl J Med 343:522-529

59. Hodis HN, Mack WJ, Azen SP, Lobo RA, Shoupe D, Mahrer PR, Faxon DP, Cashin-Hemphill L, Sanmarco ME, French WJ, Shook TL, Gaarder TD, Mehra AO, Rabbani R, Sevanian A, Shil AB, Torres M, Vogelbach KH, Selzer RH, Women's EstrogenProgestin Lipid-Lowering Hormone Atherosclerosis Regression Trial Research Group (2003) Hormone therapy and the progression of coronary-artery atherosclerosis in postmenopausal women. $\mathrm{N}$ Engl J Med 349:535-545

60. Waters DD, Alderman EL, Hsia J, Howard BV, Cobb FR, Rogers WJ, Ouyang P, Thompson P, Tardif JC, Higginson L, Bittner V, Steffes M, Gordon DJ, Proschan M, Younes N, Verter JI (2002) Effects of hormone replacement therapy and antioxidant vitamin supplements on coronary atherosclerosis in postmenopausal women: a randomized controlled trial. JAMA 288:2432-2440

61. Angerer P, Stork S, Kothny W, Schmitt P, von Schacky C (2001) Effect of oral postmenopausal hormone replacement on progression of atherosclerosis: a randomized, controlled trial. Arterioscler Thromb Vasc Biol 21:262-268

62. Hodis HN, Mack WJ, Lobo RA, Shoupe D, Sevanian A, Mahrer PR, Selzer RH, Liu Cr CR, Liu Ch CH, Azen SP (2001) Estrogen in the prevention of atherosclerosis. A randomized, double-blind, placebo-controlled trial. Ann Intern Med 135:939-953

63. Mendelsohn ME, Karas RH (2005) Molecular and cellular basis of cardiovascular gender differences. Science 308:1583-1587

64. Bray PF, Larson JC, Lacroix AZ, Manson J, Limacher MC, Rossouw JE, Lasser NL, Lawson WE, Stefanick ML, Langer RD, Margolis KL, Women's Health Initiative Investigators (2008) Usefulness of baseline lipids and C-reactive protein in women receiving menopausal hormone therapy as predictors of treatmentrelated coronary events. Am J Cardiol 101:1599-1605

65. Wild RA, Wu C, Curb JD, Martin LW, Phillips L, Stefanick M, Trevisan M, Manson JE (2013) Coronary heart disease events in the Women's Health Initiative hormone trials: effect modification by metabolic syndrome: a nested case-control study within the
Women's Health Initiative randomized clinical trials. Menopause 20:254-260

66. Hecht HS, Budoff MJ, Berman DS, Ehrlich J, Rumberger JA (2006) Coronary artery calcium scanning: clinical paradigms for cardiac risk assessment and treatment. Am Heart J 151:1139-1146

67. Zethraeus N, Borgstrom F, Jonsson B, Kanis J (2005) Reassessment of the cost-effectiveness of hormone replacement therapy in Sweden: results based on the Women's Health Initiative randomized controlled trial. Int J Technol Assess Health Care 21:433-441

68. Lekander I, Borgstrom F, Strom O, Zethraeus N, Kanis JA (2009) Cost-effectiveness of hormone replacement therapy for menopausal symptoms in the UK. Menopause Int 15:19-25

69. Lekander I, Borgstrom F, Strom O, Zethraeus N, Kanis JA (2009) Cost-effectiveness of hormone therapy in the United States. J Women's Health (2002) 18:1669-1677

70. Lekander I, Borgstrom F, Strom O, Zethraeus N, Kanis JA (2008) Cost effectiveness of hormone therapy in women at high risks of fracture in Sweden, the US and the UK-results based on the Women's Health Initiative randomised controlled trial. Bone 42: 294-306

71. Armeni E, Lambrinoudaki I, Ceausu I, Depypere H, Mueck A, Pérez-López FR, Schouw YT, Senturk LM, Simoncini T, Stevenson JC, Stute P, Rees M (2016) Maintaining postreproductive health: a care pathway from the European Menopause and Andropause Society (EMAS). Maturitas 89:63-72

72. (2017) The 2017 hormone therapy position statement of The North American Menopause Society. Menopause 24:728-753

73. Baber RJ, Panay N, Fenton A (2016) 2016 IMS Recommendations on women's midlife health and menopause hormone therapy. Climacteric 19:109-150

74. Goodman NF, Cobin RH, Ginzburg SB, Katz IA, Woode DE (2011) American Association of Clinical Endocrinologists Medical Guidelines for Clinical Practice for the diagnosis and treatment of menopause: executive summary of recommendations. Endocr Pract 17:949-954

75. (2014) ACOG Practice Bulletin No. 141: management of menopausal symptoms. Obstet Gynecol 123:202-216

76. Stuenkel CA, Davis SR, Gompel A, Lumsden MA, Murad MH, Pinkerton JV, Santen RJ (2015) Treatment of symptoms of the menopause: an endocrine society clinical practice guideline. J Clin Endocrinol Metab 100:3975-4011

77. de Villiers TJ, Hall JE, Pinkerton JV, Perez SC, Rees M, Yang C, Pierroz DD (2016) Revised global consensus statement on menopausal hormone therapy. Maturitas 91:153-155

78. Saag KG, Petersen J, Brandi ML, Karaplis AC, Lorentzon M, Thomas T, Maddox J, Fan M, Meisner PD, Grauer A (2017) Romosozumab or alendronate for fracture prevention in women with osteoporosis. N Engl J Med 377:1417-1427

79. Reginster JY, Brandi ML, Cannata-Andia J, Cooper C, Cortet B, Feron JM, Genant H, Palacios S, Ringe JD, Rizzoli R (2015) The position of strontium ranelate in today's management of osteoporosis. Osteoporos Int 26:1667-1671

Publisher's note Springer Nature remains neutral with regard to jurisdictional claims in published maps and institutional affiliations. 


\section{Affiliations}

\section{S. Rozenberg ${ }^{1}$ - N. Al-Daghri ${ }^{2}$ - M. Aubertin-Leheudre ${ }^{3}$ - M.-L. Brandi ${ }^{4,5} \cdot$ A. Cano ${ }^{6}$ - P. Collins ${ }^{7,8} \cdot$ C. Cooper ${ }^{9,10,11}$.

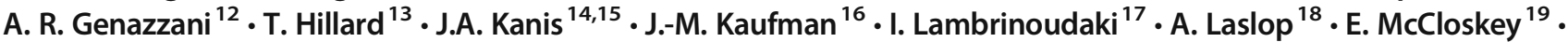 S. Palacios ${ }^{20} \cdot$ D. Prieto-Alhambra ${ }^{21} \cdot$ J.-Y. Reginster ${ }^{22,23} \cdot$ R. Rizzoli ${ }^{24} \cdot$ G. Rosano ${ }^{25} \cdot$ F. Trémollieres ${ }^{26}$. \\ N.C. Harvey ${ }^{9,10}$}

1 Department of Obstetrics and Gynecology CHU St Pierre, Université Libre de Bruxelles, Vrije Universiteit, Brussels, Belgium

2 Chair for Biomarkers of Chronic Diseases, Biochemistry Department, College of Science, King Saud University, Riyadh, Kingdom of Saudi Arabia

3 Department of Physical Activity Sciences, Faculty of Sciences, Université du Québec à Montréal, CRIUGM, Montreal, Québec, Canada

4 Department of Biochemical, Experimental and Clinical Sciences, University of Florence, Florence, Italy

5 Unit of Bone and Mineral Diseases, University Hospital of Florence, Florence, Italy

6 Department of Obstetrics and Gynecology, University of Valencia and INCLIVA Health Research Institute, Valencia, Spain

7 National Heart and Lung Institute, Imperial College London, London, UK

8 Royal Brompton Hospital, Royal Brompton Campus, Sydney Street, London, UK

9 MRC Lifecourse Epidemiology Unit, University of Southampton, Southampton, UK

10 NIHR Southampton Biomedical Research Centre, University of Southampton and University Hospital Southampton NHS Foundation Trust, Tremona Road, Southampton, UK

11 NIHR Oxford Biomedical Research Centre, University of Oxford, Oxford, UK

12 Division of Obstetrics and Gynecology, Department of Clinical and Experimental Medicine, University of Pisa, Pisa, Italy

13 Department of Obstetrics \& Gynaecology, Poole Hospital NHS Trust, Poole, UK

14 Mary McKillop Institute for Health Research, Australian Catholic University, Melbourne, Australia
15 Centre for Metabolic Bone Diseases, University of Sheffield Medical School, Sheffield, UK

16 Department of Endocrinology, Ghent University Hospital, Ghent, Belgium

17 Menopause Unit, 2nd Department of Obstetrics and Gynecology, Medical School, National and Kapodistrian University of Athens, Athens, Greece

18 Scientific Office, Federal Office for Safety in Health Care, Vienna, Austria

19 Centre for Integrated research in Musculoskeletal Ageing, Mellanby Centre for Bone Research, Department of Oncology and Metabolism, University of Sheffield, Sheffield, UK

20 Director of Palacios Institute of Women's Health, Madrid, Spain

21 Centre for Statistics in Medicine, Nuffield Department of Orthopaedics, Rheumatology and Musculoskeletal Sciences, University of Oxford, Oxford, UK

22 WHO Collaborating Center for Public Health Aspects of Musculoskeletal Health and Aging, Division of Public Health, Epidemiology and Health Economics, University of Liège, Liege, Belgium

23 Chair for Biomarkers of Chronic Diseases, Biochemistry Department, College of Science, King Saud University, Riyadh, Kingdom of Saudi Arabia

24 Division of Bone Diseases, Geneva University Hospitals and Faculty of Medicine, Geneva, Switzerland

25 IRCCS San Raffaele, Rome, Italy

26 Menopause Center, Hôpital Paule de Viguier, University Hospital of Toulouse and INSERM U1048-I2MC-Equipe 9,

Toulouse, France 